\title{
CRITICALITY SAFETY ANALYSIS OF GBC-32 SPENT FUEL CASK WITH IMPROVED NEUTRON ABSORBER CONCEPT
}

\author{
Martin Lovecký ${ }^{1}$, Jiří Závorka ${ }^{1}$, Jana Jiřičková ${ }^{1}$, and Radek Škoda ${ }^{1,2}$ \\ ${ }^{1}$ University of West Bohemia \\ Univerzitni 8, 30614 Plzen, Czech Republic \\ ${ }^{2}$ Czech Technical University \\ Zikova 1903, 16636 Prague, Czech Republic \\ lovecky@rice.zcu.cz
}

\begin{abstract}
Higher enrichment of nuclear fuel along the manufacturing limit of boron content in steel and aluminum alloys represents a significant challenge in designing spent fuel transport and storage facilities. One possible solution for spent fuel pools and casks is the burnup credit method that allows for decreasing very high safety margins associated with fresh fuel assumption in spent fuel facilities. An alternative solution based on placing neutron absorber material directly into the fuel assembly is proposed here. A neutron absorber permanently fixed in guide tubes decreases system reactivity more efficiently than absorber sheets between the assemblies. The efficiency of the newly proposed concept is demonstrated on the criticality safety analysis of the GBC-32 spent fuel cask. Absorber rods from 8 different elements are placed within Westinghouse OFA 17x17 guide tubes. Currently used boron is a good option because of high absorption cross section, low atomic mass and chemical compatibility with various alloys. Alternative options (e.g., Sm, Eu, Gd, Dy, Hf, Re, Ir) are based on very good absorbers that do not require alloy compatibility since the absorbers can be placed inside zirconium or steel cladding. Because of high efficiency of the newly proposed absorber concept, boron content in BORAL sheets can be decreased to more competitive economics. Moreover, fuel assembly pitch is investigated in order to change cask wall inner diameter that will result in lower material consumption for the cask wall with the same shielding thickness.
\end{abstract}

KEYWORDS: criticality safety, burnup credit, neutron absorber

\section{INTRODUCTION}

Criticality safety in spent fuel cask systems is commonly achieved by placing neutron absorbers in the cask basket design. Aluminum or stainless steel tubes spatially separate fuel assemblies in the cask basket. Currently, boron is exclusively used as the absorber material. The reason is the chemical and mechanical properties of light boron nuclei that can be added directly to basket tubes material, or placed in extra sheets between the tubes. Increasing fuel enrichment and limitations of boron content in the steels or alloys [1] can be solved by using burnup credit methodology in the criticality safety analysis. 
The improved neutron absorber concept is based on placing neutron absorbers directly into the fuel assembly. This solution is more efficient than absorber tubes even with neutron flux trap and allows significant basket design changes. The main changes are lowering boron content in absorber tubes and decreasing fuel assembly pitch in the basket resulting in lower cask wall diameter and total cask mass. Absorber is placed in steel cladding and fixed inside guide tubes. Because the temperature, radiation, chemical compatibility and pressure parameters are not limiting since the absorber would not be exposed to reactor core operation environment, material selection analysis is performed to optimize improved neutron absorber concept. This concept was studied recently [2], [3].

\section{CALCULATION MODEL}

GBC-32 benchmark cask is described in [4]. It is a simplified cask for burnup credit benchmark purposes. For neutron absorber concept feasibility, a 2-D model of the cask was analyzed. Fuel was assumed uniform in all fuel rods as one material. Uncertainties were not taken into account and it is assumed that they are at the same level as 2-D simplification, therefore, 0.95 limit used in the analysis.

Fuel composition was calculated with TRITON code sequence from SCALE-6.2.3 code package. Fuel assembly depletion model is depicted in Figure 1, uniform material was assumed since other parameters (fuel enrichment, fuel burnup, cooling time) have a significantly larger effect on the reactivity, especially for feasibility study. Actinide and fission product burnup credit level with NRC approved set of 28 nuclides was used. Nuclide set is very similar to French selection of 27 nuclides [5]; Eu-151 fission product makes the only difference. Isotopic correction factors were not applied since the absorber reactivity worth is around 10 times larger.

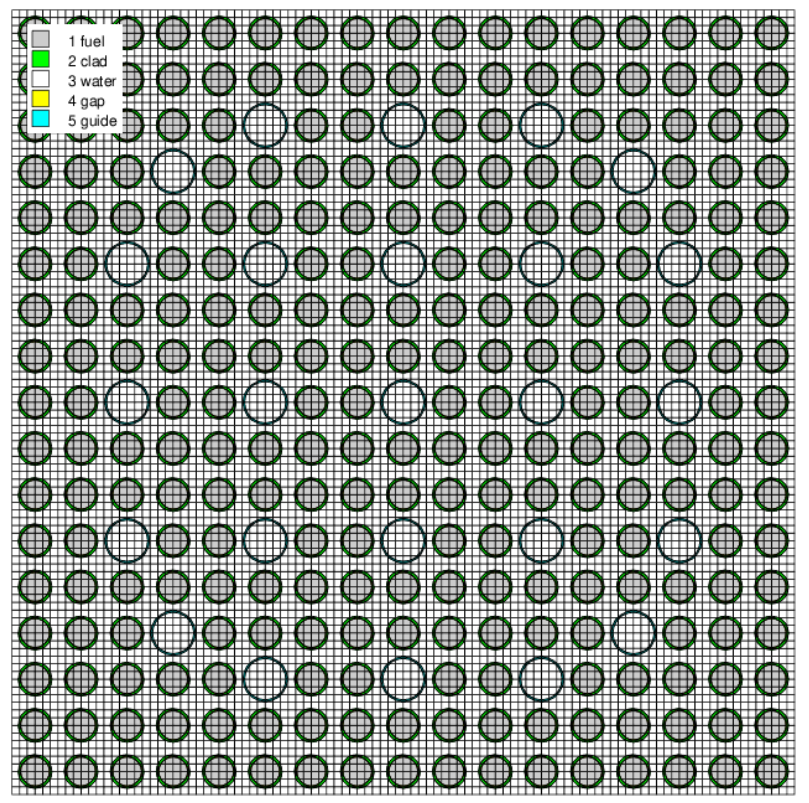

Figure 1. Fuel assembly depletion model in SCALE/TRITON.

Criticality calculations were performed with Serpent (version 2.1.31) transport code [6] and ENDF/BVIII.0 continuous energy nuclear data library [7], see Figure 2 for the geometry model. The BORAL panel is $0.2057 \mathrm{~cm}$ thick with boron density of $0.0225 \mathrm{~g} \mathrm{~B}-10 / \mathrm{cm}^{2}$. The cask is flooded with unborated water. 

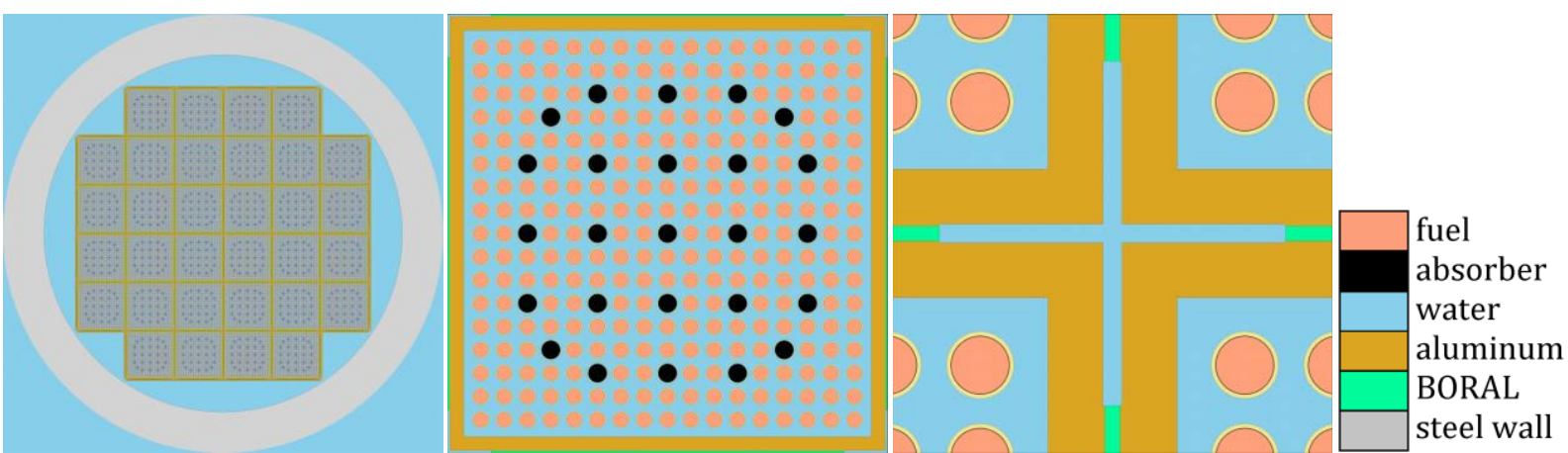

Figure 2. Spent fuel cask criticality model in Serpent 2.

\section{CALCULATION RESULTS}

GBC-32 cask criticality for benchmark specifications (Figure 3) is achieved with borated sheets placed between basket tubes. Fuel burnup influence reactivity distinctly, on the other hand, cooling time and to some extent fuel enrichment plays a minor role. Therefore, a final comparison of current solution with newly proposed neutron absorber concept is analyzed only for zero cooling time with maximum $5.0 \mathrm{wt} \%$ U-235 enrichment.

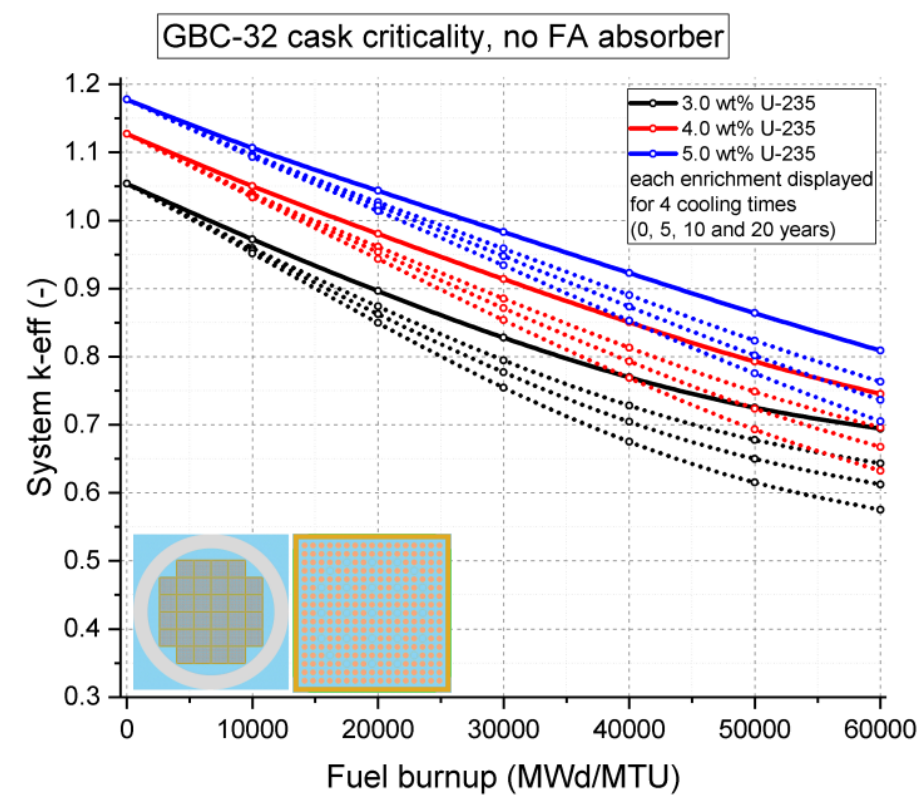

Figure 3. Spent fuel cask criticality without neutron absorber concept.

Absorber materials were selected by the most common chemical composition, one carbide, 4 oxides and 3 metals: $\mathrm{B}_{4} \mathrm{C}\left(2.52 \mathrm{~g} / \mathrm{cm}^{3}\right), \mathrm{Sm}_{2} \mathrm{O}_{3}\left(8.347 \mathrm{~g} / \mathrm{cm}^{3}\right), \mathrm{Eu}_{2} \mathrm{O}_{3}\left(7.42 \mathrm{~g} / \mathrm{cm}^{3}\right), \mathrm{Gd}_{2} \mathrm{O}_{3}\left(7.07 \mathrm{~g} / \mathrm{cm}^{3}\right), \mathrm{Dy}_{2} \mathrm{O}_{3}$ $\left(7.80 \mathrm{~g} / \mathrm{cm}^{3}\right), \operatorname{Hf}\left(13.31 \mathrm{~g} / \mathrm{cm}^{3}\right), \operatorname{Re}\left(21.02 \mathrm{~g} / \mathrm{cm}^{3}\right), \operatorname{Ir}\left(22.56 \mathrm{~g} / \mathrm{cm}^{3}\right)$. 
Absorber rod size was analyzed for 4 difference cases with inner absorber material radius from 0.1 to 0.4 $\mathrm{cm}$, outer radius was fixed to $0.45 \mathrm{~cm}$ inside $0.5 \mathrm{~cm}$ steel cladding tube, guide tube inner radius is $0.56135 \mathrm{~cm}$. Reactivity for fresh fuel in Figure 4 concluded that inner diameter should not exceed $0.2 \mathrm{~cm}$ that represents only $16 \%$ of absorber material savings. Therefore, it was decided that the absorber will not have inner hole for further studies.

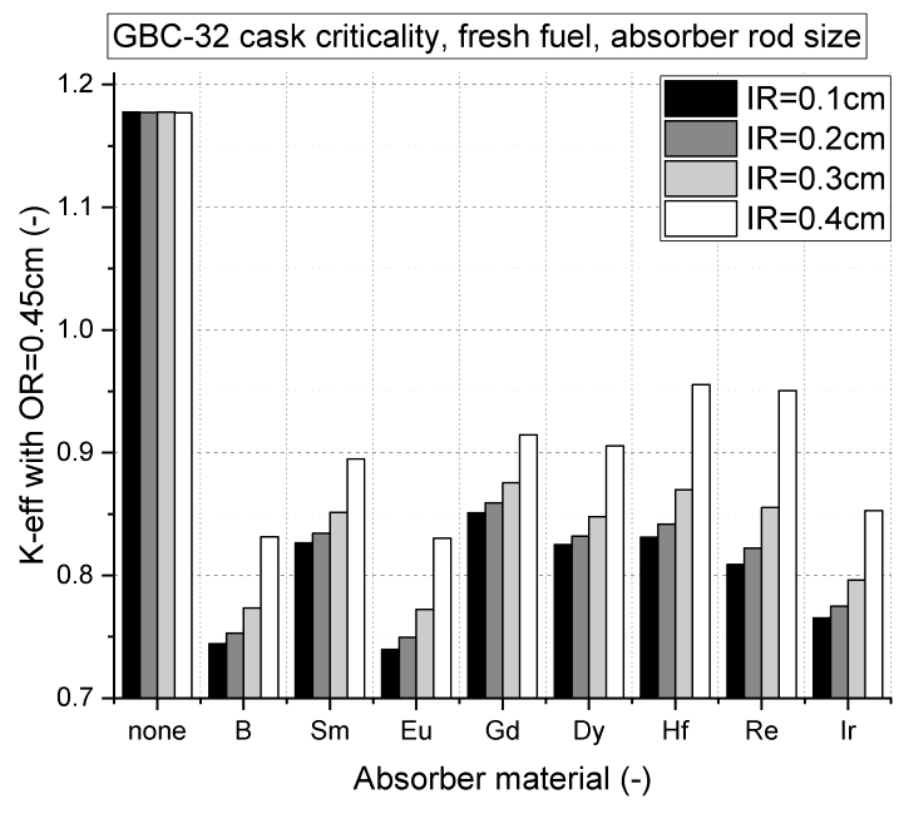

Figure 4. Absorber inner hole size selection results.

Burnup credit with no absorber rods is required for GBC-32 cask criticality safety, $35418 \mathrm{MWd} / \mathrm{MTU}$ is minimum burnup for $5.0 \mathrm{wt} \% \mathrm{U}-235$, see Figure 5. All of 8 selected absorber materials significantly decrease system reactivity and 0.95 limit is achieved with significant margin even for fresh fuel. This margin can be used for lowering boron content in BORAL sheets, see Figure 6. Without the use of burnup credit, neutron absorber concept allows decreasing BORAL content from $2.2 \%$ for the most effective absorber (europium) to $17.0 \%$ of original BORAL content for the least effective of 8 selected absorbers (gadolinium). On the other hand, if burnup credit would not be used, the cask criticality without new absorber concept would require increasing BORAL content 60 times to $6032 \%$ of original BORAL content. 


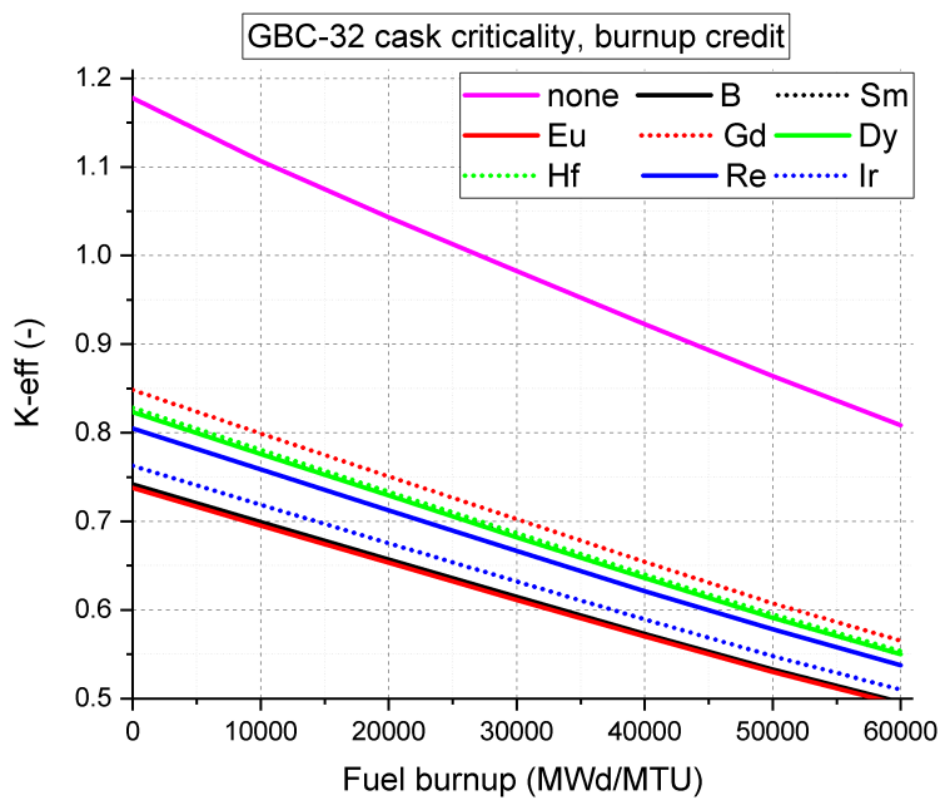

Figure 5. Burnup credit and absorber comparison.

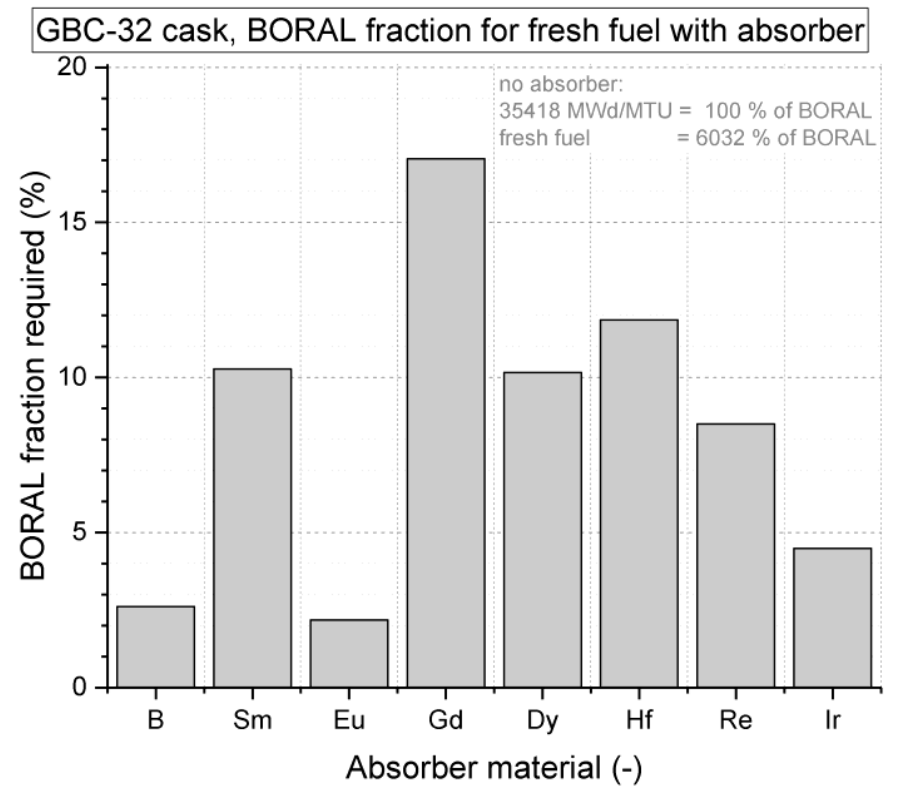

Figure 6. Decreasing boron content in BORAL sheets when improved absorbers are used.

Using both burnup credit (for $35418 \mathrm{MWd}$ /MTU, same as original GBC-32 design) and new absorber concept allows complete removal of BORAL sheets and decreasing fuel assembly pitch. Results for 222 $\mathrm{mm}$ assembly pitch are summarized in Figure 7. Only $2 \mathrm{~mm}$ thin aluminum plate between neighboring assemblies define assembly position in the cask basket. Inner cask wall radius decreased by $7.457 \mathrm{~cm}$ and consequently, cask wall mass decreased by $7.65 \%$. Moreover, system reactivity still has margins that can be used to lower the number of assemblies loaded with improved absorber concept. For this analysis, the least effective absorber (gadolinium) was analyzed, however, the conclusions are very similar to other 
absorbers. Total of 32 cases was analyzed and the optimum is loading 24 fuel assemblies, see Figures 8 and 9, no BORAL is used. Higher number of fuel assemblies loaded with the absorber generally improves safety margins. However, absorber decreases neutron flux mainly in its vicinity and uniform loading of the absorbers without direct adjacent absorbers can be as important as the number of the absorbers.

Recommended cask design changes allowed by the use of improved neutron absorber concept include:

- omitting BORAL sheet absorbers (while still using burnup credit)

- decreasing fuel assembly pitch to minimum (only $2 \mathrm{~mm}$ thin aluminum plate remained)

- decreasing inner cask wall radius by $7.457 \mathrm{~cm}$

- decreasing cask wall mass by $7.65 \%$

- 24 out of 32 fuel assemblies are loaded with the absorbers (for geometry see Figure 10)

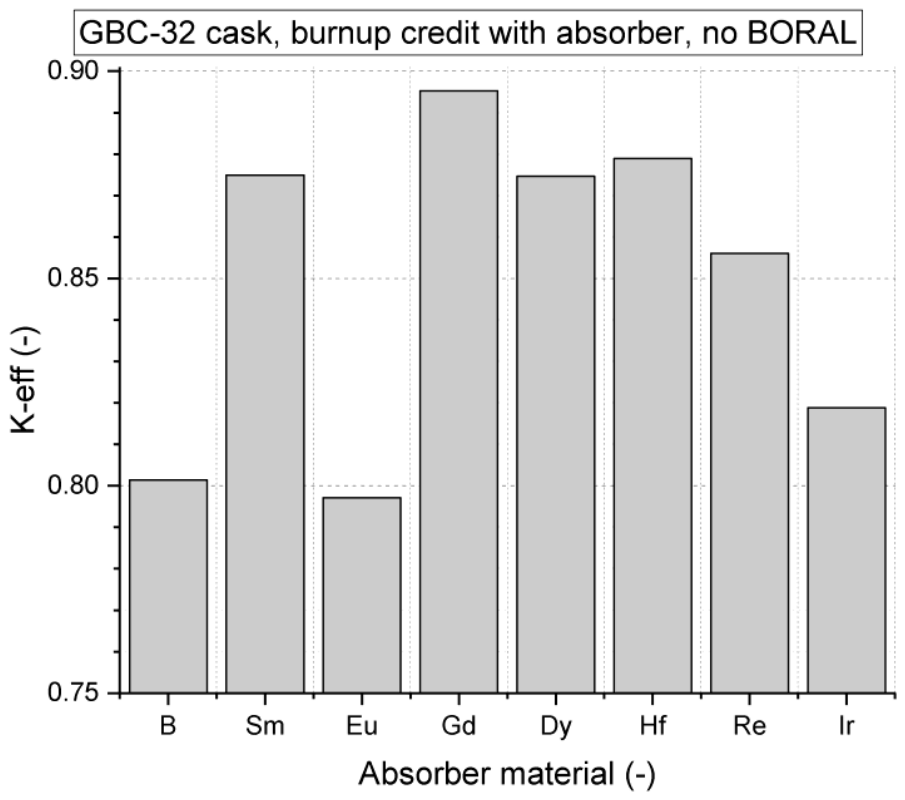

Figure 7. Burnup credit and improved absorbers for fresh fuel with lower assembly pitch.

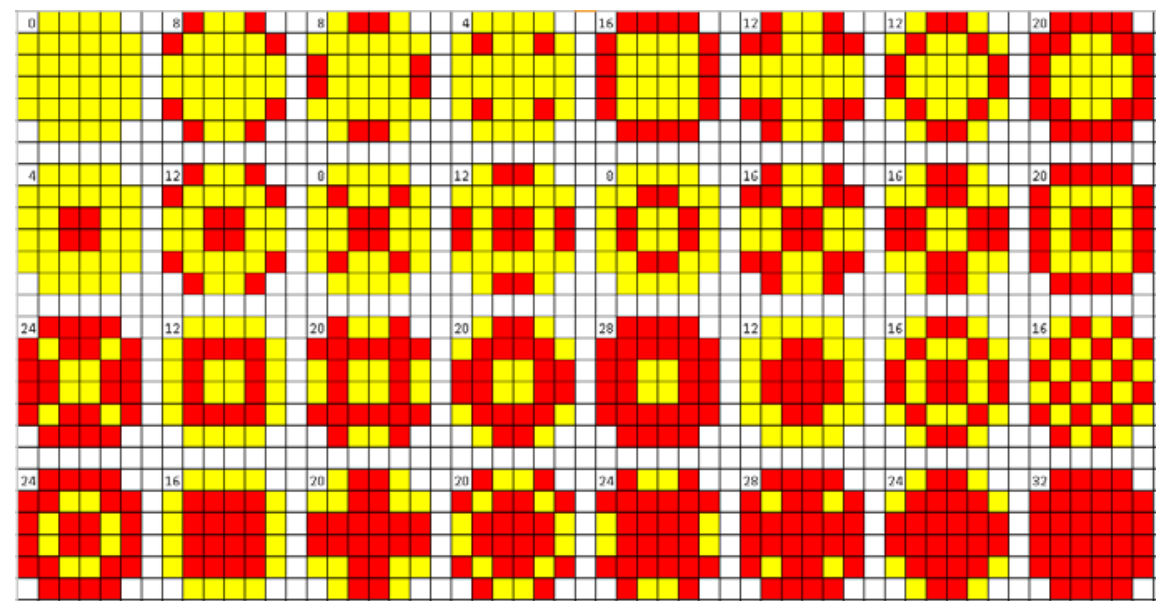

Figure 8. Determining the number of loaded absorbers $(\mathrm{red}=\mathrm{FA}+$ absorber, yellow $=$ regular FA $)$. 


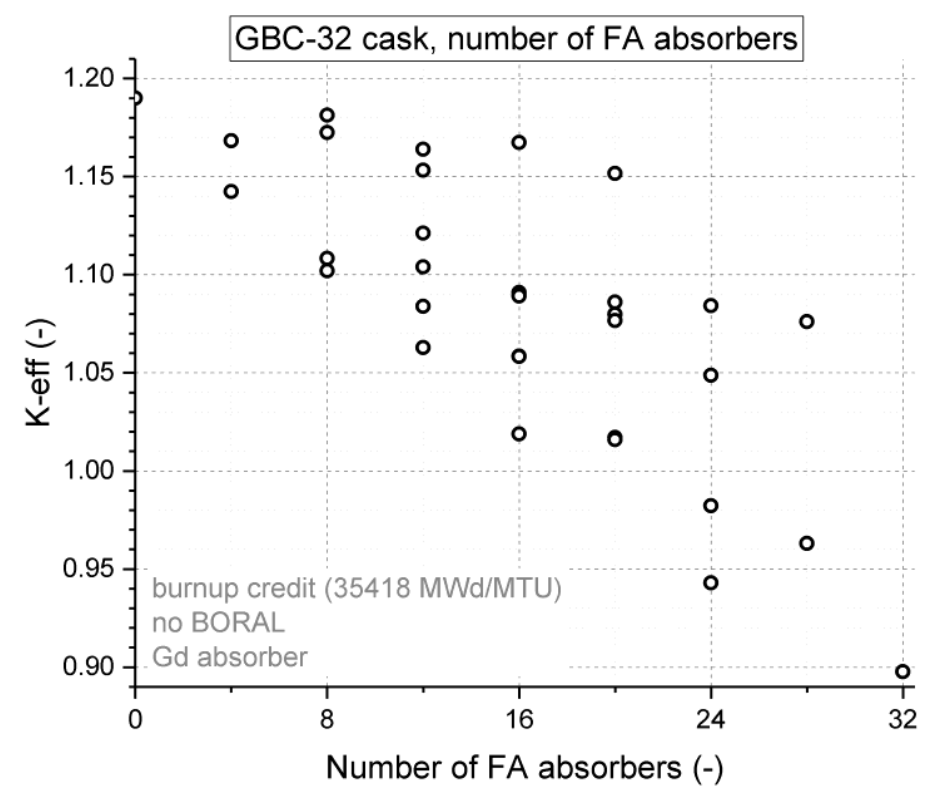

Figure 9. Choosing 24 assemblies out of 32 in the cask loaded with improved absorbers.

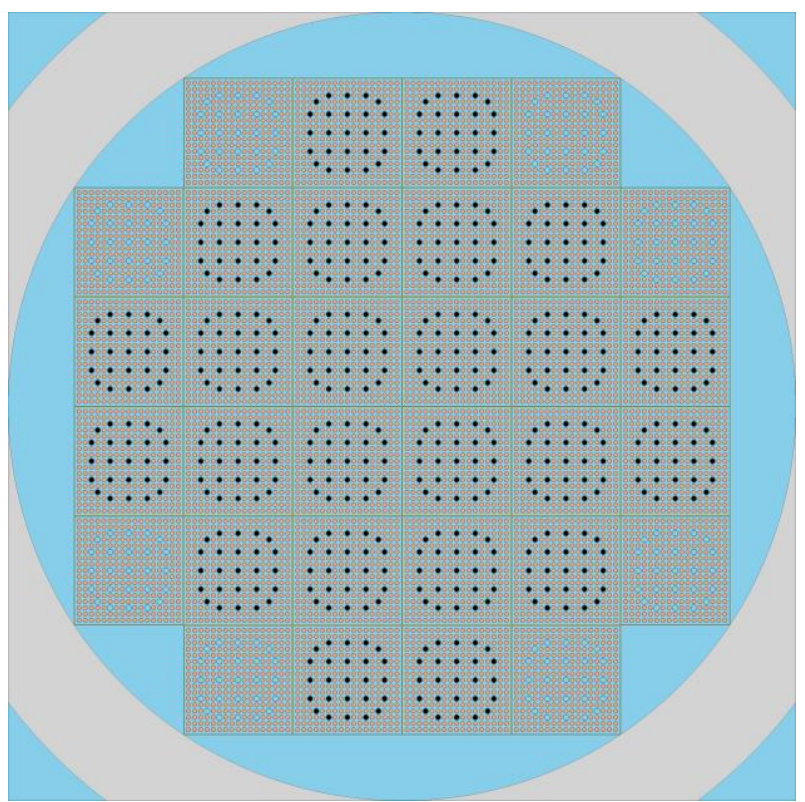

Figure 10. Proposed GBC-32 cask design changes. 


\section{CONCLUSIONS}

An improved concept of neutron absorber for GBC-32 cask criticality safety analysis is introduced. The absorber placed directly within fuel assembly guide tubes significantly decrease cask reactivity. 8 various absorber materials (B, Sm, Eu, Gd, Dy, Hf, Re, Ir) were analyzed and all of them allows cask design changes.

GBC-32 cask criticality safety is currently achieved by 2 measures: placing BORAL sheets between aluminum tubes around fuel assemblies and by using burnup credit methodology. Improved neutron absorber concept can be used in two ways:

1) Improved safety. With improved neutron absorber concept, it is possible to omit both BORAL sheets and burnup credit, therefore, only 1 measure is needed to achieve criticality safety.

2) Better economics. The two measures for criticality safety are burnup credit and improved neutron absorber concept. That allows removing BORAL sheets, decreasing fuel assembly pitch to minimum and saving cask wall mass up to around $8 \%$. Only 24 out of 32 fuel assemblies are required to be loaded by the absorbers.

Feasibility study of various ways for permanent fixation of neutron absorber and fuel assembly with the emphasis on economics is currently in development.

\section{ACKNOWLEDGMENTS}

R\&D has been funded by TK02010102 Optimization of Dry Storage for Spent Nuclear Fuel.

\section{REFERENCES}

1. J. Abenojar, F. Velasco, M. A. Martinez, "Optimization of processing parameters for the $\mathrm{Al}+10 \% \mathrm{~B} 4 \mathrm{C}$ system obtained by mechanical alloying," Journal of Materials Processing Technology 184, pp. 441446 (2007).

2. J. C. Wagner, Ch. E. Sanders, "Investigation of the Effect of Fixed Absorbers on the Reactivity of PWR Spent Nuclear Fuel for Burnup Credit," Nuclear Technology 139 pp. 91-16 (2002).

3. M. Lovecký, J. Závorka, R. Škoda, "Neutron absorber concept in spent fuel casks aiming at improved nuclear safety and better economics,". Proceedings of the 19th International Symposium on the Packaging and Transportation of Radioactive Materials (PATRAM 2019), New Orleans, USA, August 4-9, 2019.

4. J. C. Wagner, "Computational Benchmark for Estimation of Reactivity Margin from Fission Products and Minor Actinides in PWR Burnup Credit", NUREG/CR-6747, 2001.

5. L. Jutier, C. Riffard, A. Santamarina, E. Guillou, G. Grassi, D. Lecarpentier, F. Lauvaud, A. Coulaud, M. Hampartzounian, M. Tardy, S. Kitsos, "Burnup Credit Implementation for PWR UOX Used Fuel Assemblies in France: From Study to Practical Experience," Nuclear Science and Engineering 181, pp. 105-136 (2015).

6. J. Leppänen, et al., "The Serpent Monte Carlo code: Status, development and applications in 2013," Annals of Nuclear Energy 82, pp. 142-150 (2015).

7. D. A. Brown, et al., "ENDF/B-VIII.0: The 8th Major Release of the Nuclear Reaction Data Library with CIELO-project Cross Sections, New Standards and Thermal Scattering Data," Nuclear Data Sheets 148, pp. 1-142 (2018). 